\title{
TERCEIRA IDADE: \\ o discurso dos experts e a produção do "novo velho"
}

\author{
Regina Duarte Benevides de Barros ${ }^{1}$ \\ Adriana Miranda de Castro ${ }^{2}$
}

\begin{abstract}
"Lá onde a alma pretende se unificar, lá onde o Eu inventa para si uma identidade ou uma coerência, o genealogista parte em busca do começo - dos começos inumeráveis que deixam esta suspeita de cor, esta marca quase apagada que não saberia enganar um olho, por pouco histórico que seja; a análise da proveniência permite dissociar o Eu e fazer pulular nos lugares e recantos de sua síntese vazia, mil acontecimentos agora perdidos."
\end{abstract}

Michel Foucault

\section{Resumo}

O presente trabalho objetiva desnaturalizar a categoria da terceira idade. A partir da revisão bibliográfica de alguns autores importantes no campo da Gerontologia e no diálogo com Foucault, Deleuze e Guattari argumentamos que a produção desta subjetividade "novo velho" articula-se a outros vetores de existencialização presentes no contemporâneo. Palavras-chave: Subjetividade; Modos de existir; Terceira Idade; Velho; Gerontologia.

\begin{abstract}
This paper argues the third age cathegory like a natural stage of life and shows that it is a historical product. After a bibliographyc revision of some important Gerontology's authors and using the work of Foucault, Deleuze and Guattari we be able to say that "new old people" represent

${ }^{1}$ Psicóloga, Professora Adjunta do Departamento de Psicologia da Universidade Federal Fluminense (UFF), Niterói - RJ. Doutora em Psicologia Clínica. E-mail: rebenevi@terra.com.br

${ }^{2}$ Psicóloga, Universidade do Estado do Rio de Janeiro (UERJ), Mestranda em Psicologia (UFF), Niterói

- RJ. E-mail: dricamc@terra.com.br
\end{abstract}


an artificial form to designate the elderly people which is a production of many factors on contemporary society.

Keywords: Sujectification Forces; Life Style; Third Age; Elderly People; Gerontology.

\section{Introdução}

Nossa sociedade tem valorizado sobremaneira o discurso científico como pilar na adoção ou não de determinadas atitudes, comportamentos e valores. Este fato evidencia-se no espaço crescente que cada novo estudo acadêmico ganha nos campos midiáticos. A mídia não se cansa em difundir os "dados" e conclusões das pesquisas que se debruçam sobre o humano, alvo de um escrutínio cada vez mais minucioso, a fim de divulgar e produzir modos de existência que "garantam" um viver melhor ou, dizendo de outra forma, a qualidade de vida. A ação de divulgação generalizante de tais discursos tornando-os "naturais", funciona como um dos dispositivos ${ }^{3}$ de ratificação e legitimação das especialidades técnico-científicas bem como dos "objetos-sujeitos" sobre os quais legisla.

É trilhando este caminho que as pesquisas sobre o envelhecer vem ganhando uma atenção cada vez maior, fazendo circular o discurso dos experts e vinculando qualidade de vida na velhice a certo tipo de práticas de sentir, pensar, falar e agir nomeando o campo como o da terceira idade.

A justificativa para o número crescente de pesquisas, debates, seminários e programas de televisão, artigos em revistas de grande circulação sobre o envelhecimento tem utilizado como argumento de maior força a teoria da transição epidemiológica descrita por Omran ${ }^{4}$. Esta teoria pretende articular as alterações no padrão saúde/doença com seus condicionantes e conseqüências no campo da demografia, sociologia e economia (VERAS, 1994).

\footnotetext{
${ }^{3}$ Com o termo dispositivo, Foucault (1993, p. 244), tenta delimitar um conjunto bastante heterogêneo que inclui discursos, instituições, leis, medidas administrativas, organizações arquitetônicas, enunciados científicos e proposições morais e/ou filosóficas; as quais se articulam num tipo de jogo ou rede, mudando de posição e/ou função conforme a urgência que se lhes apresente em dado momento histórico, lhes exigindo resposta. Cabe ao dispositivo uma função-ação estratégica.

${ }^{4}$ OMRAN, A. R. The Epidemiologic Transition: a theory of epidemiology of population change. Milbank Memorial Fund Quarterly, Oxford, v. 49, n. 4, p. 509-538, Apud VERAS, R., 1994, p. 28.
} 
Aliado à teoria da transição epidemiológica, a escassez de recursos disponíveis no setor da saúde pública (que, por isto mesmo, precisam ser aplicados com grande resolutibilidade), o alto custo dos procedimentos médico-hospitalares para os mais velhos, a exclusão social dos mesmos frente a um mercado altamente competitivo, as mudanças na estrutura familiar e o impacto econômico ocasionado pelo aumento da população de inativos constróem as principais pontes da associação envelhecimento/problema social (VERAS, 1994; PAPALÉO NETTO; PONTE, 1996; DEBERT; NERI, 1999; GORDILHO, 2000).

Alguns autores no campo de estudo sobre o velho salientam que o envelhecimento pode ser definido a partir de fatores biológicos somente em parte, pois será sempre marcado pelo contexto sócio-histórico em que se insira, o qual lhe dará sentido (PEIXOTO, 1998; MERCADANTE, 1996; DEBERT; 1998). Outros, ainda, destacam que a velhice não se transforma em questão social em conseqüência direta do aumento do número de velhos, mas pela atuação do discurso científico sobre o envelhecimento na legitimação desta "verdade", uma vez que um problema social é sempre produzido (DEBERT, 1998; LIMA, 1999). Embora tais autores destaquem seja a confluência dos fatores biológicos e sociais, seja o caráter de produção do fenômeno social, parece-nos que a discussão permanece ainda distante da operação de desnaturalização deste "novo velho" pois não coloca em análise o processo mesmo de fabricação, de categorização e de hegemonização de certos modos de existir típicos dos discursos contemporâneos sobre a velhice.

A possibilidade de construção de uma análise desnaturalizadora é, para nós, correlata à compreensão de que toda a realidade é artifício, é uma configuração formal que faz ver e falar certos modos de sentir, agir e pensar que são constituídos no confronto de forças sócio-históricopolíticas. A realidade, aqui, não se mostra como campo homogêneo de necessidades naturais que em sua evolução alcançaria um novo patamar para os sujeitos que aí se encontram.

No nosso caso, o velho não seria simplesmente um objeto de investigação/explicação das ciências da saúde, por exemplo, que estariam sendo solicitadas a outras respostas face ao progresso técnico-científico que aumentou os anos de expectativa de vida. Queremos tomar a questão neste exato ponto em que o "novo velho" é emergência do cruza- 
mento de vários vetores (tecnológicos, biológicos, políticos, sociais, históricos, midiáticos, etc) que constituem tanto os especialistas em velhice quanto os corpos-velhos investidos por estes mesmos saberes.

Assim, parece-nos importante deslocar a discussão das justificativas epidemiológicas e/ou sócio-históricas para a análise da emergência do "sujeito-objeto" velho. Trata-se, portanto, de apreendê-lo enquanto modo de existir, expressão de um certo modo de subjetivação. Acreditamos que cabe argüir a proveniência do "novo velho" enquanto alvo de um conjunto de práticas e saberes que o objetivam sob o nome de terceira idade e problematizar as contingências sócio-históricas de sua produção.

\section{Cartografando Práticas e Saberes acerca dos Mais Velhos ou a Produção da Terceira Idade}

Leme (1999) e Secco (1999) através da análise de distintos períodos históricos evidenciam a existência de outros parâmetros na abordagem do velho e de continuidades e rupturas no pensamento ocidental sobre este tema. Seus trabalhos enfatizam a busca das chamadas prémedicina e medicina em definir a imagem daquilo que seria a velhice, o papel dos mais jovens no cuidar dos velhos, as mazelas do envelhecimento e os cuidados (em especial de higiene e regramento no estilo de vida) para que este processo fosse "saudável".

Na Grécia, a cosmogonia era marcada por uma visão mítica do existir, não havendo dialetização de contrários - juventude e velhice não se opunham. Contudo, nos séculos IX e VIII a.C. as transformações sócio-políticas gregas rompem com a visão cíclica do viver, concebendo uma nova estrutura em função das novas relações de poder e sua conseqüente hierarquização. Esta cosmogonia da cisão, do viver dicotomizado, faz da velhice o prenúncio da morte abrindo espaço para as teorias do calor intrínseco - princípio essencial à vida, cuja tendência era a lenta extinção. Os velhos têm seu valor diminuído de maneira que o sistema gerontocrático de organização do socius é gradativamente abandonado (SECCO, 1999).

Assim como na Grécia, em Roma também os velhos perderão seu valor na medida em que houver alterações na configuração do poder político, o qual passará das mãos do Senado às dos militares - jovens 
homens conquistadores (SECCO, 1999). No cenário romano, cabe destacar dois autores do campo médico: Aulus Cornélius Celsus (10-37d.C.) e Galeno (129-200d.C.), cuja influência no pensamento sobre os cuidados com a saúde e prescrições dietéticas, farmacêuticas e ambientais serão retomadas e marcarão os estudos desenvolvidos nos séculos XV e XVI. Ambos salientavam o auto-cuidado e a auto-responsabilidade pela saúde e pelo velho. ${ }^{5}$

Neste período a idade dos velhos não ia muito além dos quarenta anos e chegar aos sessenta ou mais anos de idade constituía exceção. Porém, o que nos interessa salientar é que não há um período histórico onde a velhice tenha sido "naturalmente" respeitada e valorizada. Observa-se nas descrições de Leme (1999) e Secco (1999) que o prestígio do velho relacionava-se não à sua característica de velho, mas ao lugar de poder que ocupava na hierarquia social.

Na Idade Média, voltada para as guerras religiosas, segue a valorização da juventude e estabelece-se uma idéia paradoxal de velhice, que, comparada à primeira, é fraca e decrépita, mas que dentro dos padrões morais cristãos, onde a morte constitui-se no melhor caminho para a remissão dos pecados, é valorizada por estar próximo à salvação (SECCO, 1999). Segundo Leme (1996), na sociedade medieval, o saber médico manteve como base a perspectiva galênica, centralizando-se em medidas higienistas não só ao nível individual mas também relativas à população.

O Renascimento irrompe exaltando os ideais clássicos da estética greco-romana e voltando-se para as conquistas marítimas e, mais uma vez, o velho está fora dos padrões valorizados. Todavia, se assiste a um aumento no interesse sobre o tema da velhice aparentemente atrelado ao desenvolvimento de novas tecnologias de produção de conhecimento. Os avanços da Química, Patologia, Fisiologia e Anatomia nos séculos XVII e XVIII ampliam as discussões acerca do envelhecer e lhe concedem outros contornos almejando separar velhice normal da velhice doente (LEME, 1999). Assistimos, então, ao aperfeiçoamento dos mecanismos disciplinares (FOUCAULT, 1993), que passam a funcionar como forma de gestão dos homens capaz de manejar suas multiplicidades usan-

\footnotetext{
${ }^{5}$ Veremos mais adiante que este tema do auto-cuidado/auto-responsabilidade se tornará um dos vetores principais nos textos e pesquisas sobre o envelhecimento no século XX.
} 
do-as no sentido de aumentar a eficiência no trabalho. Segundo Foucault (1993, p. 198), a organização social centralizada na gestão econômica do trabalho precisa organizar dispositivos entorno dos traços biológicos da população a fim de assegurar sua sujeição e, principalmente, sua crescente utilidade na produção de lucro.

A visão do velho passa a estar vinculada a esta lógica da produtividade de modo que ele não é necessariamente um doente, mas é aquele que não é capaz de produzir.

A infância e a velhice, excluídas dos círculos de produção, pairam, idealizadas, acima da condição humana. [. . . ] A velhice passa a ser encarada como uma segunda infância, cabendo ao velho o ócio como recompensa pelos anos de trabalho. [...] Esta concepção romântica da velhice é ambígua e paradoxal, uma vez que o velho, por não ser uma força produtiva, perde totalmente sua função social. (SECCO, 1999, p. 19-20)

Nas últimas décadas do século XIX e no início do século XX os anciãos vão gradativamente perdendo qualquer aura de nobreza ou sabedoria. Nesta época, a população de velhos cresce e pode-se pensar que começa, de forma mais evidente, o esboço de um "problema social" pois sucedem na cena sócio-histórica fatores como: a improdutividade do velho, a visão linear ascendente e descendente do ciclo vital (nascer, crescer, ter o ápice na maturidade e declinar até a velhice e a morte), a institucionalização do próprio curso de vida (dimensão fundamental do crescente processo de individualização), a ênfase na dimensão biológica do envelhecimento e a conseqüente universalização deste processo, o advento das aposentadorias, o surgimento dos asilos de velhos que baseados na caridade reconhecem esta população como alvo diferenciado de práticas institucionais e a tomada da idade cronológica como aparato cultural e legal definidor de espaços sociais (DEBERT, 1998; GROISMAN, 1999; LIMA, 1999; SECCO, 1999).

Segundo Lima (1999) é neste "caldo", onde se intrincam cientificismo, positivismo e transformações na estrutura social que o discurso sobre o velho alcançará o status e especialidade científica. Geriatria e Gerontologia nascem como especialidades médicas, no início do século $\mathrm{XX}$, calcadas numa série de modificações na forma da medicina olhar a 
doença e o corpo que envelhece, constituindo o que $\mathrm{Katz}^{6}$ (1996) denominou de discurso da senescência, cujo objetivo era diferenciar corpo jovem/corpo idoso e envelhecimento normal/envelhecimento patológico.

A moderna Geriatria toma como seu marco inicial a publicação do livro do médico Ignatz Leo Nascher ${ }^{7}$ : Geriatrics: the diseases of old age and their treatments (1914). Segundo Nascher, o envelhecimento era um processo de degeneração celular. Ele consagra seu trabalho à descrição pormenorizada da forma de diferenciação dos velhos a partir de seus corpos não se restringindo, entretanto, a este aspecto já que propõe a existência de uma combinação entre declínio celular interno e declínio físico externo que agiriam sobre as características mentais e comportamentais do velho (GROISMAN, 1999; LEME, 1999).

Observa-se o debruçar do olhar médico sobre o corpo a fim de esquadrinhá-lo, enquadrá-lo e torná-lo alvo de práticas de assujeitamento. O corpo é objeto da ciência que o define como velho, decrépito, propondo-se a "solucionar" este problema com as necessárias prescrições que assegurassem a qualidade de vida. ${ }^{8}$

Segundo Debert (1999), os discursos iniciais da Gerontologia:

"[...] pertenciam ao campo médico e tratavam do envelhecimento orgânico, visto com desgaste fisiológico. Esse discurso é abordado em obras especializadas, encarregadas de difundir o saber e propor medidas de higiene corporal, relacionadas com o retardamento do envelhecimento." (p. 31)

Já em meados do século XX começa-se a acompanhar um movimento multidisciplinar na Gerontologia que extrapola a ação sobre o corpo envelhecido para controlar a velhice fora dos consultórios médicos. Este momento ganha relevo porque para além da apresentação de soluções para os problemas do envelhecimento, passam a se preocupar com estratégias de fortalecimento de autoridade do próprio campo da Gerontologia.

\footnotetext{
${ }^{6}$ KATZ, S. Disciplining Old Age: the formation of gerontological knowledge. Charlottesville: Virginia University, 1996. Apud GROISMAN, D, 1999, p. 51.

${ }^{7}$ NASCHER, Leo. Geriatrics: the diseases of old age and their treatment. 1914. Apud GROISMAN, 1999, p. 51.

${ }^{8}$ A Gerontologia introduzida por Élice Metchnikoff, em 1903, através do texto The Nature of Man é definida como o estudo do potencial alargamento da vida por meio das intervenções médicas (GROISMAN, 1999).
} 
De acordo com Debert (1998), o discurso gerontológico altera-se a partir do momento em que com a aposentadoria institucionalizada, surgem os problemas econômicos que vão ganhar lugar cativo e de crescente importância no âmbito político-administrativo. Isto constituirá campo fértil para demógrafos, sociólogos e psicólogos que, sob a chancela da Gerontologia, vão demarcar as necessidades dos aposentados apresentando soluções de "bem-estar" assim como calculando e recalculando as cobranças de tributos para fazer face às "despesas" com as aposentadorias.

No período de 1959 a 1967, conforme Guillemard9 (1986), a sensibilidade em relação à velhice desloca-se da idéia predominante de pobreza para a de solidão e marginalidade. Este deslocamento faz do estilo de vida o campo privilegiado de intervenção da Gerontologia, exigindo a criação de novas formas de classificação - surge aí a "terceira idade" (PEIXOTO, 1998; DEBERT, 1999).

Cria-se, pois, um "novo velho" - um velho que deve se manter afastado do envelhecimento através da prática de atividades físicas e mentais, as quais lhe garantiriam a manutenção de suas capacidades funcionais e, em última análise, de sua juventude.

Se até o final dos anos 60 as duas grandes teorias que dominavam o cenário gerontológico - teoria da atividade e teoria do desengajamento ${ }^{10}$-, enfatizavam a velhice como momento de perda dos papéis sociais e interessavam-se em entender como se dava o ajustamento pessoal frente a ela, com a fabricação deste "novo velho" o contexto muda.

Surge, atrelada a uma visão integradora ou holística do ser humano, a noção de envelhecimento bem sucedido, veiculando três vieses: a afirmação de um potencial individual biopsicossocial considerado adequado pelo sujeito e seu grupo etário para alcançar o bem-estar geral; a associação do funcionamento do velho bem-sucedido ao funcionamento da média da população mais jovem de modo que ambos sigam próximos em termos de desempenho; e o desenvolvimento de mecanismos de compensação e oti-

${ }^{9}$ GUILLEMARD, A. M. Le decline du social: formation et crise des politiques de la vieillesse. Paris: PUF, 1986. Apud DEBERT, G., 1999, p.75.

${ }^{10}$ Resumidamente, para a "Teoria da Atividade" (CAVAN, R. Family Tensions Between the Old and Middleaged. Springfield: Thomas, 1965. Apud LIMA, M., 1999, p. 23-63) o idoso seria mais feliz se investisse em atividades compensatórias, mantendo-se ativo. Ao contrário, para a "Teoria do Desengajamento" (CUMMING, H; HENRY, W. Growing Old. New York: Appleton, 1961 Apud LIMA, 1999, p. 23-63) o comportamento mais adequado seria o desengajar-se voluntário das atividades. 
mização que signifiquem a manutenção de competência nos diversos domínios do funcionamento humano - cognição, afetividade, sociabilidade, criatividade e memória, por exemplo. (DEBERT; NERI, 1999)

Envelhecimento bem sucedido, qualidade de vida e terceira idade implicam na circulação da idéia de um velho identificado como fonte de recursos - autônomo, capaz de respostas criativas frente às mudanças sociais, disponível para re-significar identidades anteriores, relações familiares e de amizade. Assim, sociabilidade, lazer e educação (como estratégia de socioterapia e de manutenção da "mente ativa") fazem-se dispositivos privilegiados de intervenção junto a esta população e ganham espaço significativo na mídia para a criação e divulgação de uma "nova velhice" (DEBERT, 1999; LIMA, 1999; GUEDES, 2000).

Entretanto, em que pese a importância desses novos vetores que funcionam quebrando os estereótipos de incapacidade, improdutividade, rigidez, abandono e solidão, não se pode esquecer que as forças impulsionadoras do movimento de criação da "terceira idade" são forças políticas e estão atreladas também ao modo de funcionamento da sociedade capitalística ${ }^{11}$ conforme se modulou na contemporaneidade. Assim, estão em jogo nesta produção os interesses econômicos e políticos envolvidos em conquistar uma população de velhos potencialmente consumidora de bens e serviços e de crescente poder na cena social, bem como a criação de categorias que possam dar conta de apreender as forças do próprio viver.

Debert (1999) afirma que o discurso gerontológico tem agido num duplo movimento: um no sentido de uma crescente socialização das formas de gestão do processo do envelhecimento e o outro na direção de "reprivatização da velhice" - na medida em que se enfatiza a responsabilidade individual no modo como cada um envelhece ou se deixa envelhecer (dicotomia cuidado/desleixo), principalmente através do uso intensivo dos dipositivos midiáticos e da produção de espaços sociais em torno do velho. Eis que o tema do auto-cuidado e da auto-responsabilidade reaparece séculos mais tarde, desta vez utilizado como parte das estratégias de ordenamento e controle do socius na contemporaneidade.

\footnotetext{
${ }^{11}$ Seguimos aqui o conceito proposto por Guattari (1986) ao se referir às características do modo de produção capitalista encontradas no contemporâneo seja em sociedades assumidamente capitalistas, seja em sociedades ditas socialistas.
} 
De nossa parte, consideramos que mais do que uma reprivatização encontramo-nos frente à radicalização de um projeto privatizante, intimizante e identitário de apreensão da existência. Tal é o projeto implementado pela lógica capitalística hegemônica no corpo social na medida em que o processo de produção do "novo velho" não difere em muito daquele que gestou em tempos anteriores a infância e a adolescência (ARIÈS, 1981).

Sem dúvida são fundamentais os eixos de análise destacados pelos autores que vêm empreendendo pesquisas sobre o envelhecimento no Brasil especialmente aqueles que estão comprometidos com o estabelecimento das políticas públicas. Segundo Debert (1999), há quatro vetores que ao se combinarem indicariam algumas sínteses possíveis sobre a situação brasileira do velho: (1) a ameaça imediata de uma explosão demográfica, exigente de crescentes gastos públicos para atender às demandas dos idosos; (2) a crítica ao "capitalismo selvagem" no contexto brasileiro que exclui àquele que não é capaz de produzir; (3) a tendência da cultura brasileira em valorizar a novidade em detrimento de suas próprias tradições que impõe ao velho o isolamento; e (4) o declínio da família extensa no Brasil, em especial nos espaços urbanos, que combinado à incapacidade estatal de solucionar problemas básicos para a melhoria das condições de vida da população em geral, coloca os idosos bastante vulneráveis.

Consideramos, entretanto, necessário destacar que tais vetores, como outros apontados anteriormente, estão articulados na composição do tecido sócio-político contemporâneo que expressa um modo dominante de subjetivação. Temos chamado este modo de viver hegemônico de modoindivíduo (BENEVIDES DE BARROS, 1994). Este modo de subjetivação, construído ao longo dos séculos XVII/XVIII ganha não apenas dominância, mas também contornos importantes nos séculos XIX/XX.

É em especial na virada para o século XX que a experiência sóciopolítico-subjetiva se intimiza, refluindo o espaço público de gestão da vida para o espaço privado (SENNET, 1988). Tal modo de subjetivação no campo da experiência vivida é marcado pela operação de interiorização psicológica, de intimização dos afetos e pela construção de uma identidade-verdade sobre si. Mas será desde os anos 60/70 que presenciaremos uma gradativa, porém contundente, ação de transnacionalização do capi- 
tal, globalização do mercado, esvaziamento dos Estados-nação e criação de mecanismos regulatórios de gestão da vida. Estaríamos frente a um modo de ação do poder como exercício ativo de controle da vida - biopoder, onde "[...] a nova medicina sem médico nem doente, [que] resgata doentes potenciais e sujeitos à risco [...]” (DELEUZE, 1992, p. 225).

\section{Conclusão}

Parece-nos fundamental, a partir do diálogo com Foucault (1993), Deleuze (1992) e Guattari (1986), tentar provocar aqui um ponto de bifurcação e evidenciar o desafio que existe para todos aqueles que se interessam por esta nova "categoria" que promete ser, no século XXI, uma das que demandará ações de constante problematização.

Tomar o "novo velho" como identidade fixada indicaria, a nosso ver, ações estigmatizadoras, tanto quanto aquelas que anteriormente estavam postas, como vimos, sobre o "velho". Entretanto, se estes "novos velhos" forem tomados para além da capacidade de auto-cuidado e autoresponsabilidade, categorias ainda bastante marcadas pelo modo-indivíduo, todos aqueles que deles "cuidam" terão que levar em conta esta potência de reinvenção e de reinterpretação do mundo e de si.

Aqui consideramos que a produção de certos modos de existir como foco (alvo) de intervenção de práticas e discursos especializados não pode ser entendida fora de uma reflexão que esteja atenta ou que inclua análises das modulações do capitalismo tal como se apresenta contemporaneamente.

\section{Referências}

1 ARIÈS, P. História Social da Criança e da Família. $2^{\text {a }}$ ed. Rio de Janeiro: Guanabara-Koogan, 1981.

2 BENEVIDES DE BARROS, R. D. Grupos: a afirmação de um simulacro. 1994. Tese (Doutorado em Psicologia Clínica) - Pontifícia Universidade Católica de São Paulo, São Paulo, 1994.

3 DEBERT, G. G. A Reinvenção da Velhice: socialização e processos de reprivatização do envelhecimento. São Paulo: EdUSP/FAPESP, 1999.

4 IDEM. A Antropologia e o Estudo dos Grupos e das Categorias de Idade. In: BARROS, M. M. L. (Org.) Velhice ou Terceira Idade? estudos antropológicos sobre identi- 
dade, memória e política. Rio de Janeiro: Fundação Getúlio Vargas, 1998. p. 49-67.

5 DEBERT, G. G.; NERI, A. L. (Org.) Velhice e Sociedade. Campinas: Papirus, 1999.

6 DELEUZE, G. Conversações. Rio de Janeiro: Editora 34, 1992.

7 FOUCAULT, M. Microfísica do Poder. 11ª .ed. Rio de Janeiro: Graal, 1993.

8 GORDILHO, A. et alii. Desafios a Serem Enfrentados no Terceiro Milênio pelo Setor Saúde na Atenção ao Idoso. Rio de Janeiro: UnATI / UERJ, 2000.

9 GROISMAN, D. Velhice e História: perspectivas teóricas. Cadernos IPUB, Rio de Janeiro, n.10, p. 43-56, 1999. Número especial: Envelhecimento e Saúde Mental - Uma Aproximação Multidisciplinar.

10 GUATTARI, F. Micropolítica: cartografias do desejo. $2^{\mathrm{a}}$ ed. Petrópolis: Vozes, 1986.

11 GUEDES S. L. A Concepção sobre a Família na Geriatria e na Gerontologia Brasileiras: ecos dos dilemas da multidisciplinaridade. Revista Brasileira de Ciências Sociais, São Paulo, v. 15, n. 43, p. 1-20, 2000.

12 LEME, L. E. G. A Gerontologia e o Problema do Envelhecimento. Visão Histórica. In: PAPALÉO NETTO, M. Gerontologia - a velhice e o envelhecimento em visão globalizada. São Paulo: Atheneu, p. 13-25. 1999.

13 LIMA, M. A. A Gestão da Experiência de Envelhecer em um Programa para a Terceira Idade: a UnATI / UERJ. Textos sobre Envelhecimento - UnATI/ UERJ, Rio de Janeiro, ano 2, n.2, p. 23-63, $2^{\circ}$ sem. 1999.

14 MERCADANTE, E. Aspectos Antropológicos do Envelhecimento. In: PAPALÉO NETTO, M. Gerontologia - a velhice e o envelhecimento em visão globalizada. São Paulo: Atheneu, 1996. p. 73-76.

15 PAPALÉO NETTO, M.; PONTE, J. R. Envelhecimento: desafio na transição do século. In: Idem. Gerontologia - a velhice e o envelhecimento em visão globalizada. São Paulo: Atheneu, 1996. p. 3-12.

16 PEIXOTO, C. Entre o Estigma e a Compaixão e os Termos Classificatórios: velho, velhote, idoso, terceira idade... In: BARROS, M. M. L. (Org.). Velhice ou Terceira Idade? Estudos antropológicos sobre identidade, memória e política. Rio Janeiro: Fundação Getúlio Vargas, 1998. p. 69-84.

17 SECCO, C. L. T. R. As Rugas do Tempo na Ficção. Cadernos IPUB, Rio de Janeiro, n. 10, p. 9-33, 1999. Número especial: Envelhecimento e Saúde Mental - Uma Aproximação Multidisciplinar.

18 SENNET, R. O Declínio do Homem Público: as tiranias da intimidade. São Paulo: Cia das Letras, 1988.

19 VERAS, R. País Jovem com Cabelos Brancos: a saúde do idoso no Brasil. $3^{\text {a }}$.ed. Rio de Janeiro: Relume Dumará /UERJ, 1994. 